\title{
Fetomaternal outcome in women with heart disease in urban population in a tertiary care hospital
}

\author{
Preeti Sharma*, Renuka Malik
}

Department of Obstetrics and Gynecology, PGIMER and Dr. RML Hospital, New Delhi, India

Received: 03 July 2018

Revised: 29 July 2018

Accepted: 01 August 2018

\author{
*Correspondence: \\ Dr. Preeti Sharma, \\ E-mail: medicalgroup101@gmail.com
}

Copyright: (c) the author(s), publisher and licensee Medip Academy. This is an open-access article distributed under the terms of the Creative Commons Attribution Non-Commercial License, which permits unrestricted non-commercial use, distribution, and reproduction in any medium, provided the original work is properly cited.

\begin{abstract}
Background: Heart disease in pregnancy is still a major problem worldwide, particularly in low resource country like India. Its reported incidence varies between 0.1 to $4 \%$. Heart disease complicates $1 \%$ to $3 \%$ of all pregnancies and is responsible for $10 \%$ to $15 \%$ of maternal mortality. In India, the rheumatic heart disease (RHD) contributes to approximately $70 \%$ of heart disease seen in pregnancy. Heart disease in pregnancy is associated with adverse fetomaternal outcome and has re-emerged as one of the leading causes of maternal mortality. The maternal mortality rate in women with cardiac disease is $7 \%$ and morbidity is $30 \%$ during pregnancy in India.

Methods: This study was a prospective observational study conducted in the department of obstetrics and gynaecology at PGIMER \& Dr. RML hospital from Nov 2015 to March 2017. 35 Pregnant women with heart disease were taken as study group and 35 low risk pregnant patients were taken as control. Multiple pregnancy and any other medical disorder like GDM, PIH, IHCP and thyroid disorders were excluded from study. Fetomaternal outcome in terms of POG at delivery, mode of delivery, prematurity, LBW, NICU admission and maternal and neonatal mortality were compared between these two groups.

Results: Vaginal delivery is still the common mode of delivery. Preterm delivery, prematurity, ICU admission, low birth weight is more common in pregnancy with heart disease than in normal pregnancy.

Conclusions: Although maternal mortality and fetal mortality is reduced, pregnancy with heart disease still carries substantial risk to mother and child.
\end{abstract}

Keywords: Adverse fetomaternal outcome, Heart disease, Incidence

\section{INTRODUCTION}

Heart disease in pregnancy is still a major problem worldwide, particularly in low resource country like India. Its reported incidence varies between 0.1 and $4 \% .^{1,2,3}$

Heart disease complicates $1 \%$ to $3 \%$ of all pregnancies and is responsible for $10 \%$ to $15 \%$ of maternal mortality. ${ }^{4}$ In India, the rheumatic heart disease (RHD) contributes to approximately $70 \%$ of heart disease seen in pregnancy. ${ }^{5}$ The maternal mortality rate in women with cardiac disease is $7 \%$ and morbidity is $30 \%$ during pregnancy in India. ${ }^{6,7}$ It is an important indirect cause of maternal mortality in India. There are very few studies available in India that is prospective, focused particularly on heart disease in pregnancy. Most studies were retrospective and used small sample size. This prospective study was carried out to compare fetomaternal outcome in an effort to improve the management. 


\section{METHODS}

This study was a prospective observational study conducted in the department of obstetrics and gynaecology at PGIMER and Dr. RML hospital from November 2015 to March 2017. 35 Pregnant women with heart disease were enrolled in the study who fulfilled the inclusion criteria and 35 low risk pregnant patient were taken as control in third trimester. Multiple pregnancy and any other medical disorder like GDM, PIH, IHCP, thyroid disorders were excluded from study. Patients with heart disease presented in any trimester who has no absolute contraindication of pregnancy like pulmonary artery hypertension of any cause, severe systemic ventricular dysfunction (LVEF $<40 \%$ in NYHA III and IV), previous peripartum cardiomyopathy with any residual impairment of left ventricular function, severe mitral stenosis and severe symptomatic aortic stenosis, Marfan syndrome with aorta dilated $>45 \mathrm{~mm}$, aortic dilatation $>50 \mathrm{~mm}$ in aortic disease associated with bicuspid aortic valve or native severe coarctation) were included in the study group. Fetomaternal outcome in terms of POG at delivery, mode of delivery, prematurity, LBW (Low Birth Weight), NICU (Neonatal Intensive Care Unit) admission and maternal and neonatal mortality were compared between these two groups. All the patients were explained about the study and a written and informed consent was taken.

\section{RESULTS}

Incidence: This prospective study was conducted in PGIMER and Dr. RML hospital, Delhi from November 2015 to March 2017 in the department of obstetrics and gynaecology. 35 patients with heart disease were taken along with 35 normal patients as control. During the course of study total 1301 deliveries were conducted in present tertiary care institution. The incidence of heart disease was $2.69 \%$ during the study duration.

\section{Characteristics of the study participants}

Age

In the study population with 35 pregnant women with heart disease who fulfilled the inclusion criteria and 35 controls were taken. The mean age was 26.14 \pm 3.97 years in the study population while in control group mean age was $26.37 \pm 4.19$ years which was comparable. In both the groups women who were less than 30 years $(85.71 \%)$ were 30 and more than 30 years $(14.29 \%)$ were $05(\mathrm{p}=1)$.

\section{$B M I$}

In the study population BMI ranges from 20.2-36.28 $\mathrm{kg} / \mathrm{m}^{2}$ in case group while in control group it was between 17.3-33.64 $\mathrm{kg} / \mathrm{m}^{2}$. Mean BMI was $26.26 \pm 4.54 \mathrm{~kg} / \mathrm{m}^{2}$ and $25.49 \pm 4.21 \mathrm{~kg} / \mathrm{m}^{2}$ respectively in case and control group which was comparable.

\section{Parity}

In the study population 8 were primigravidae $(22.86 \%)$, 25 were multigravida $(71.43 \%)$ and 2 were grand multipara $(5.71 \%)$ while in control group 12 were primigravidae (34.29\%), 23 were multigravida (65.71\%).

\section{Enrolment in the study}

In present study population 6 patients were enrolled in first trimester $(17.14 \%), 16$ in second $(45.71 \%)$ and 13 in third trimester $(37.14 \%)$ while controls were enrolled during third trimester.

\section{Etiology of heart disease}

In present study population RHD was seen in 26 cases (74.29\%), CHD in 5 cases (14.29\%) and cardiomyopathy (CMP) in 4 cases $(11.4 \%)$. RHD was the most common cardiac lesion $(74.29 \%)$ followed by CHD (14.29\%) and Cardiomyopathies $(11.4 \%)$ as depicted in Figure 1.

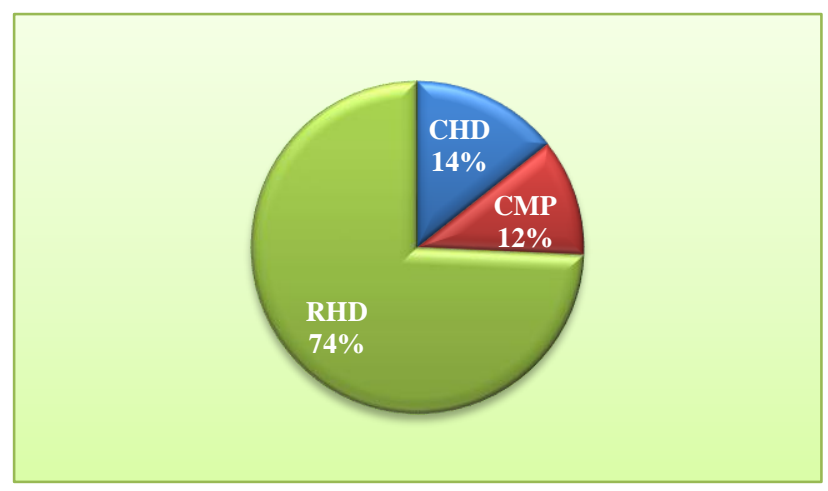

Figure 1: Etiology of heart diseases in study population.

Of all the cases with RHD, MS was seen in 11 cases $(31.42 \%)$, MR in $10(28.50 \%)$, PAH in 10 cases (28.50\%), TR in 2 cases $(5.71 \%)$ and AS in 1 case $(2.86 \%)$. Severe MS was seen in 8 patients $(22.85 \%)$, severe PAH in 7 cases $(20 \%)$ cases, severe AS in 1 case $(2.86 \%)$ and severe MR in 2 cases $(5.71 \%)$ shown in Figure 2.

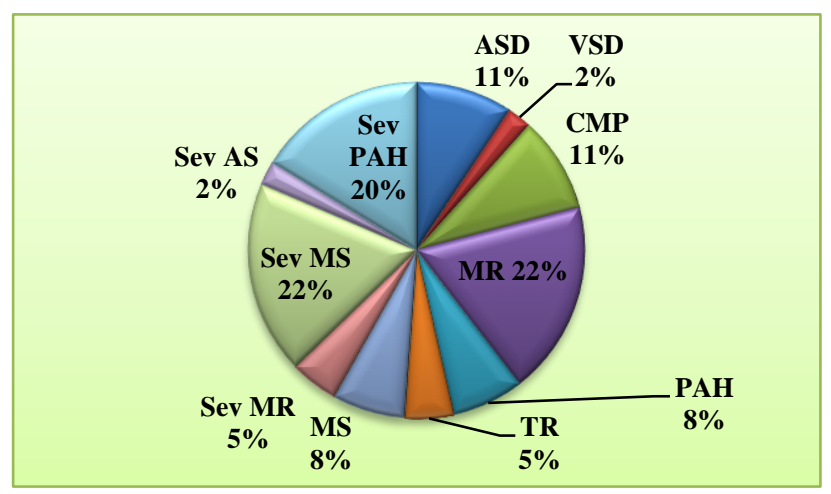

Figure 2: Distribution of cardiac lesions. 
In present study population 17 patients (48.57\%) were diagnosed with heart disease prior to pregnancy and rest were diagnosed during the present pregnancy $(25.71 \%)$. No patient had preconceptional counselling done. In patient with MS 8 patients were surgically corrected $(30.76 \%)$ prior to pregnancy. 4 patients had MVR $(15.38 \%)$ and 4 had commissurotomy (15.38\%). DCM was seen in $3(8.57 \%)$ and one patient had peripartum cardiomyopathy. In those with CHD, ASD was observed in $4(11.42 \%)$ and VSD in $1(2.86 \%)$. In CHD 2 patients had surgical correction (40\%) done, one for ASD and other for VSD.

\section{Maternal outcome}

\section{Timing of delivery}

In the study population there were 10 preterm deliveries (28.57\%) among cases whereas 03 in control population $(8.57 \%)$ which was not statistically significant $(\mathrm{P}=0.062)$ shown in Figure 3. There were $25(71.43 \%)$ term deliveries in cases and $32(91.43 \%)$ in controls.

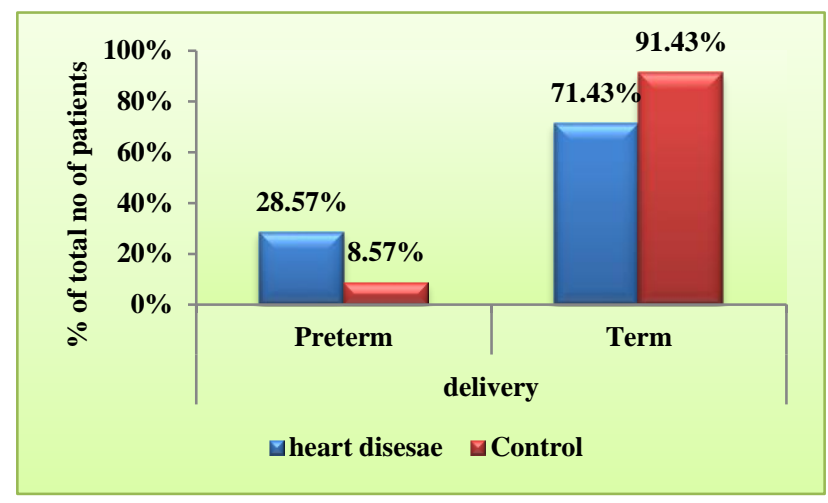

Figure 3: Comparison of term and preterm deliveries between study and control group.

\section{Mode of delivery}

There were 22 women with heart disease that delivered through normal vaginal delivery $(62.86 \%)$ while 26 in control group (74.29\%). Three $(8.51 \%)$ had vacuum delivery in heart disease group as compared to none in control group. Rate of Caesarean deliveries was not statistically significant in both groups $(n=13,37.14 \%$ versus $\mathrm{n}=09,25.71 \%, \mathrm{P}=0.303$ ). Only three caesareans were performed for cardiac indication in the heart disease group in contrast to none in control group.

\section{Adverse fetal outcome}

Fetal outcome was assessed in study population for prematurity, NICU admissions, LBW and fetal mortality. There were 13 NICU admission in heart disease population (37.14\%) while 06 in control group (17.14\%) that was not significant in the study population $(\mathrm{P}=0.060)$ shown in Figure 4.

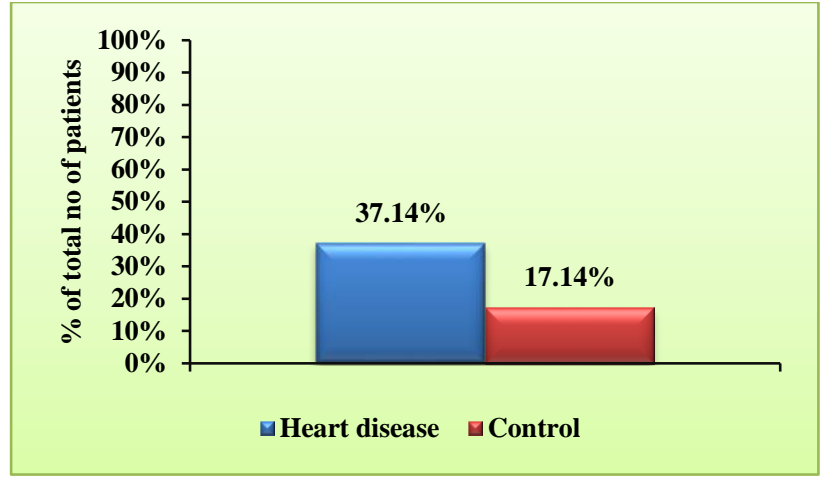

Figure 4: Comparison of NICU admission in the study and control group.

Prematurity was seen in 09 cases in heart disease population $(25.71 \%)$ and 02 cases in control population $(5.88 \%)$ which was significant $(\mathrm{P}=0.045)$ shown in Figure 5.

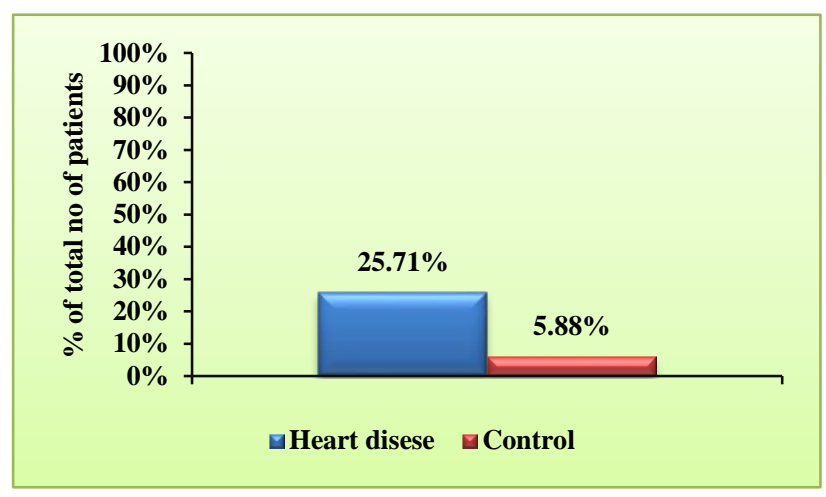

Figure 5: Comparison of prematurity between study and control group.

As shown in Figure 6 LBW was seen in 15 babies with maternal heart disease $(42.86 \%)$ and in 09 babies in control group $(25.71 \%)$ which was significant $(\mathrm{P}=0.131)$ and there was no fetal mortality in any of the groups. No baby was born with congenital heart disease whose mother had CHD.

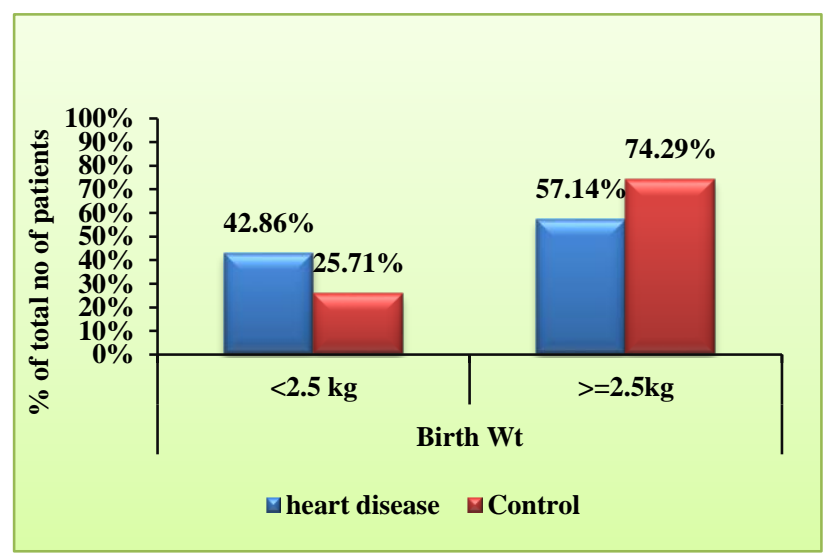

Figure 6: Comparison of birth weight between study and control group. 


\section{DISCUSSION}

Most studies in pregnant women with heart disease were done by cardiologist and worsening of cardiac status was taken as adverse outcome. This prospective study was conducted in PGIMER and Dr. RML hospital, New Delhi from November 2015 to March 2017.35 cardiac patients and 35 controls were taken. The incidence of heart disease in pregnancy in present study was $2.69 \%$, similar to the incidence seen in other earlier Indian studies. ${ }^{4,8-10}$

The mean age was $26.14 \pm 3.97$ years and mean BMI was $26.26 \pm 4.54 \mathrm{~kg} / \mathrm{m} 2$ in the study population while in control group mean age was $26.37 \pm 4$.19years and mean BMI was $25.49 \pm 4.21 \mathrm{~kg} / \mathrm{m} 2$ which was comparable. In both the groups 30 patients were less than 30 years $(85.71 \%)$ and 5 patients were more than 30 years 05 $(14.29 \%)$. In present study age and BMI was not found to be associated with adverse fetomaternal outcome whereas parity and time of enrolment of the study was found to be correlated with the adverse fetal outcome. In an Indian study done by Hiralal $\mathrm{K}$ et al found that increased maternal age was a risk factor for poor maternal and neonatal outcome which was not observed in the present study. ${ }^{5}$ Sheela CN et al in their study done in 2009 found that parity was not significantly associated with any adverse maternal outcome which was in corroboration with the present study. ${ }^{9}$ In the study population 8 $(22.86 \%)$ were primigravida, $25 \quad(71.43 \%)$ were multigravida and $2(5.71 \%)$ were grand multipara while in control group $12(34.29 \%)$ were primigravida , 23 $(65.71 \%)$ were multigravida. In present study authors observed that multiparity was significantly associated with LBW $(\mathrm{P}=0.045)$ on univariate regression analysis. In present study 6 patients were enrolled in $(17.14 \%)$ in first trimester, $16(45.71 \%)$ in second and $13(37.14 \%)$ in third trimester in the study population while controls were enrolled during third trimester as per protocol. In present study authors found that rate of NICU admissions was significantly high in women who enrolled in second trimester with heart disease $(\mathrm{p}=0.043)$. Similar findings were observed by study done by Sheela CN et al in 2011 observed that on univariate regression analysis late booking after 20 weeks had adverse effect on fetomaternal outcome. ${ }^{9}$ Martin LC et al in 2016 conducted a study in which he concluded that maternal age, parity and enrolment in third trimester were not associated with adverse fetomaternal outcome. ${ }^{11}$ Present study showed RHD was most common cardiac lesion followed by CHD. Most previous studies done in developing countries also showed the similar result. ${ }^{5,12-14}$

\section{Comparison of feto maternal outcome between control and study population}

\section{Timing of delivery}

Preterm deliveries complicated $28.57 \%$ of the patients with heart disease whereas $8.57 \%$ in control population which was not statistically significant $(\mathrm{P}=0.062)$. Indian study by HU Doshi reported $27.7 \%$ of preterm deliveries in the heart disease group. ${ }^{12}$ After reviewing the literature also authors found that preterm delivery is more common in heart disease than in normal pregnancy. ${ }^{15,16}$

\section{Mode of delivery}

Spontaneous vaginal delivery was the commonest mode of delivery among patient with heart disease. There were 22 women with heart disease that delivered through normal vaginal delivery $(62.86 \%)$ while 26 in control group $(74.29 \%)$. Similar findings were observed in other Indian studies. ${ }^{5,8-10}$ Three had vacuum delivery in heart disease group $(8.51 \%)$ to cut short the second stage of labour as compared to none in control group. The number of Caesarean deliveries was higher in heart disease group $(\mathrm{n}=13,37.14 \%$ vs. $\mathrm{n}=09,25.71 \%, \mathrm{P}=0.303)$. All LSCS were done electively. No emergency LSCS was done in patients with heart disease. All these patients had better outcome that can be explained by the fact that patients were managed successfully by multidisciplinary approach. Caesarean section was performed for obstetric indication in $20.6 \%$ patients in study by Bagde ND. ${ }^{14}$

\section{Maternal mortality}

There was no maternal mortality in present study population. This was also the finding of some Indian studies..$^{8,12}$ Whereas some studies reported maternal mortality. ${ }^{5,17}$

\section{ICU stay}

ICU stay was significantly higher in heart disease group $(\mathrm{p}=0.0004)$ with 13 ICU admissions (31.43\%). Ten patients developed pulmonary oedema/cardiac failure $(28.57 \%)$ during the study period which was medically managed. In a study conducted by Hiralal $\mathrm{K}$ there was $7.4 \%$ cardiac failure. ${ }^{5}$ Incidence of cardiac failure reported by Bengal VB was $2.86 \%$ which was less compared to present study. ${ }^{8}$

\section{Fetal outcome}

There was more adverse outcome in heart disease group than in control group. There was significantly higher incidence of Prematurity (25.71\% vs. $5.88 \%, \mathrm{P}=0.045)$, NICU admission (37.14\% vs.17.14, $\mathrm{P}=0.060)$ and LBW $(42.86 \%$ vs. $25.71 \%, \mathrm{P}=0.131)$ which was in accordance with other studies. ${ }^{5,17}$ In present study there was no fetal mortality in any of the groups.

\section{CONCLUSION}

RHD was the most common heart disease followed by CHD. MS and ASD was the commonest lesion among RHD and CHD respectively. Heart disease in pregnancy is a high-risk pregnancy requiring round the clock monitoring by cardiologist and anaesthetist especially in severe cases for an optimal fetomaternal outcome. 
Funding: No funding sources

Conflict of interest: None declared

Ethical approval: The study was approved by the Institutional Ethics Committee

\section{REFERENCES}

1. Roos-Hesselink JW, Ruys TP, Stein JI, Thilén U, Webb GD, Niwa K, et al. Outcome of pregnancy in patients with structural or ischaemic heart disease: results of a registry of the European Society of Cardiology. Eur Heart J. 2013;34(9):657-65.

2. Regitz-Zagrosek V, Blomstrom Lundqvist C, Borghi C, Cifkova R, Ferreira R, Foidart J-M, et al. ESC Guidelines on the management of cardiovascular diseases during pregnancy. The task force on the management of cardiovascular diseases during pregnancy of the European society of cardiology (ESC). Eur Heart J. 2011;32:3147-97.

3. Ashrafi R, Curtis SL. Heart Disease and Pregnancy. Cardiol Ther. 2017;6(2):157-73.

4. Nanna M, Stergiopoulos K. Pregnancy complicated by valvular heart disease: an update. J Am Heart Ass: Cardiovasc Cerebrovasc Dis. 2014;3(3):e000712.

5. Hiralal K, Chaudhuri S. Pregnancy complicated by maternal heart disease: a review of 281 women. J Obstet Gynecol India. 2012;62(3):301-6.

6. Pushpalatha K. Cardiac diseases in pregnancy- A review. JIMSA. 2010;23(4):269-74.

7. Sharma P, Malik R, Pandit N. Risk factors in pregnancy with heart disease and their co-relation with adverse feto-maternal outcome. Int J Reprod Contracept Obstet Gynecol. 2018;7(3):1135-41.

8. Bangal VB, Singh RK, Shinde KK. Clinical study of heart disease complicating pregnancy. IOSR J Pharma. 2012;2(4):25-8.

9. Sheela CN, Karanth S, Patil CB. Maternal cardiac complications in women with cardiac disease in pregnancy. Int J Pharm Biomed Res. 2011;2(4):2615.
10. Nagamani G, Bhavani K, Isukapalli V, Lagudu S. Heart disease in pregnancy prospective study from southern India. Int J Current Med Appl Sci. 2015;6(1):8-12.

11. Martins LC, Freire CMV, Capuruçu CAB, Nunes M do CP, Rezende CA de L. Risk prediction of cardiovascular complications in pregnant women with heart disease. Arquivos Brasileiros de Cardiologia. 2016; 106(4):289-96.

12. Doshi Hu, Roza HV, Tekani M, Modi K. Cardiac disease in pregnancy-maternal and perinatal outcome. J Indian Med Assoc. 2010;5:108:278-80.

13. Ghuge SH, Patil VV, Latti RG, Thorat KD. A comparative study of cardiovascular sympathetic activity in three trimesters of pregnancy. Pravara Med Rev. 2011;3(1):19-23.

14. Bagde ND, Bagde MN, Shivkumar PV, Tayade S. Clinical profile and obstetric outcome in pregnancy complicated by heart disease.: a five year Indian rural experience. Int $\mathbf{J}$ Reprod Contracept Obstet Gynecol. 2013;2(1):52-7.

15. Cunnigham FG, Lenovo KJ, Bloom SJ, Hauth JC, Rouse DJ, Spong CY. Cardiovascular disorders. In: Cunnigham FG, ed. Williams Obstetrics, $23^{\text {rd }}$ edn. United States: McGraw-Hill education; 2010:958.

16. Bhatla N, Mahey R, Yadav R. The cardiac case. In: Mishra, ed. Ian Donald 's Practical Obstetric Problems, $7^{\text {th }}$ edn. New Delhi: Wolters Kluwer India Pvt Ltd; 2012:176.

17. Nayak RG, Patil SK, Laddad MM. Pregnancy with heart disease-fetomaternal outcome. Int $\mathrm{J}$ Recent Trends Sci Technol. 2014;11(2):169-72.

Cite this article as: Sharma $\mathrm{P}$, Malik R.

Fetomaternal outcome in women with heart disease in urban population in a tertiary care hospital. Int $\mathrm{J}$ Reprod Contracept Obstet Gynecol 2018;7:3684-8. 